\title{
Capillary Leak Syndrome Likely the Result of Granulocyte Colony-Stimulating Factor after High-Dose Chemotherapy
}

\author{
Eiichi Oeda, Kenji Shinohara, Shinji Kamei, Jun Nomiyama and Hirofumi Inoue
}

\begin{abstract}
Two cases of malignant lymphoma complicated with capillary leak syndrome following super high-dose chemotherapy and administration of granulocyte colony-stimulating factor (G-CSF) are presented. Subsequent to the nadir of granulocytes, and at the stage of rapid increase of granulocytes, the symptoms of fever, hypotension, dyspnea, pleural effusion and edema appeared, and laboratory data revealed hypoxia, hypocapnia and hypoalbuminemia. In addition, an abscesslike lesion was observed in the liver in one patient. After the administration of G-CSF was ceased or decreased, and pulse therapy with methylprednisolone was initiated, these symptoms disappeared quickly.

(Internal Medicine 33: 115-119, 1994)
\end{abstract}

Key words: chemotherapy, growth factor, dyspnea, methylprednisolone

\section{Introduction}

The use of hematopoietic growth factors which act on granulocyte and macrophage committed stem cells, i.e., granulocyte colony-stimulating factor (G-CSF) and granulocyte macrophage-colony stimulating factor (GM-CSF), has been found to decrease the duration of agranulocytosis infectious episodes associated with bone marrow suppression after chemotherapy or bone marrow transplantation (1-4). Adverse effects due to these agents include rash, bone pain, weight gain, edema, pleural and pericardial effusions, and pulmonary thrombus (14). Rare cases of capillary leak syndrome characterized by weight gain, peripheral edema, pleural effusion, pulmonary infiltrates, hypoxia and hypotension caused by the administration of GM-CSF $(1,2,5)$, interleukin-2 (IL-2) (6) and tumor necrosis factor (TNF) (7) have been reported. However, there have been no reports of capillary leak syndrome caused by GCSF (8). We present two cases of capillary leak syndrome likely due to G-CSF, which were successfully treated by cessation or reduction of G-CSF dose and pulse therapy with methylprednisolone.

\section{Case Report}

Case 1

The patient was a 38-year-old male who was diagnosed with malignant lymphoma of the oral tonsil in May 1990. He received autologous bone marrow transplantation on February 24, 1992, during the first remission (Fig. 1). The preconditioning regimen consisted of mitoxantrone (MIT) $7 \mathrm{mg} / \mathrm{m}^{2}$, cytosine arabinoside (Ara-C) $1.5 \mathrm{~g} / \mathrm{m}^{2} / 12$ hours, 2 times/day, and etoposide (VP-16) $300 \mathrm{mg} / \mathrm{m}^{2} / \mathrm{day}$, from days -5 to -3 . The administration of G-CSF, $300 \mu \mathrm{g} /$ day by intravenous infusion was begun on day 0 . On day 9 , the granulocyte count began to increase. On day 11 , there was pyrexia of $38^{\circ} \mathrm{C}-39^{\circ} \mathrm{C}$, when the granulocytes had increased to $5.6 \times 10^{9} / \mathrm{L}$. On day 13 , the patient complained of dyspnea, and pleural effusions were seen on the chest $\mathrm{X}$-ray (Fig. 2). At that time, granulocytes increased to $16.2 \times 10^{9} / \mathrm{L}, \mathrm{CRP}$ was $27.0 \mathrm{mg} / \mathrm{dl}, \mathrm{PO}_{2}$ was $63.0 \mathrm{mmHg}$, and $\mathrm{PCO}_{2}$ was $31.4 \mathrm{mmHg}$. The serum albumin level, $4.0 \mathrm{~g} / \mathrm{dl}$ on day 15 , decreased to $2.7 \mathrm{~g} / \mathrm{dl}$ on day 18 , and the hematocrit value, $44.0 \%$ on day 14 , decreased to $32.6 \%$ on day 18 . At this time, serial blood cultures were performed; but, no evidence of bacterial or fungal infection was found.

A diagnosis of capillary leak syndrome was made on the basis of blood gas analysis and laboratory findings. The discrepancy between serum albumin and hematocrit on day 18 was due to anemia of chemotherapy induced marrow suppression. An oxygen mask was supplied, and pulse therapy with methylprednisolone (m-PSL) was initiated. The administration of G-CSF was stopped for 2 days, with a subsequent rapid drop in granulocyte count; $\mathrm{G}-\mathrm{CSF}$ was then started again at a reduced dose, on day 21. The fever dropped on day 17 , pleural effusion disappeared and CRP improved to $1.4 \mathrm{mg} / \mathrm{dl}$ on day 21 . Also on

From the Division of Hematology, Department of Medicine, Yamaguchi Prefecture Central Hospital, Hofu

Received for publication July 19, 1993; Accepted for publication December 20, 1993

Reprint requests should be addressed to Dr. Kenji Shinohara, the Division of Hematology, Department of Medicine, Yamaguchi Prefecture Central Hospital, Hofu, 747 

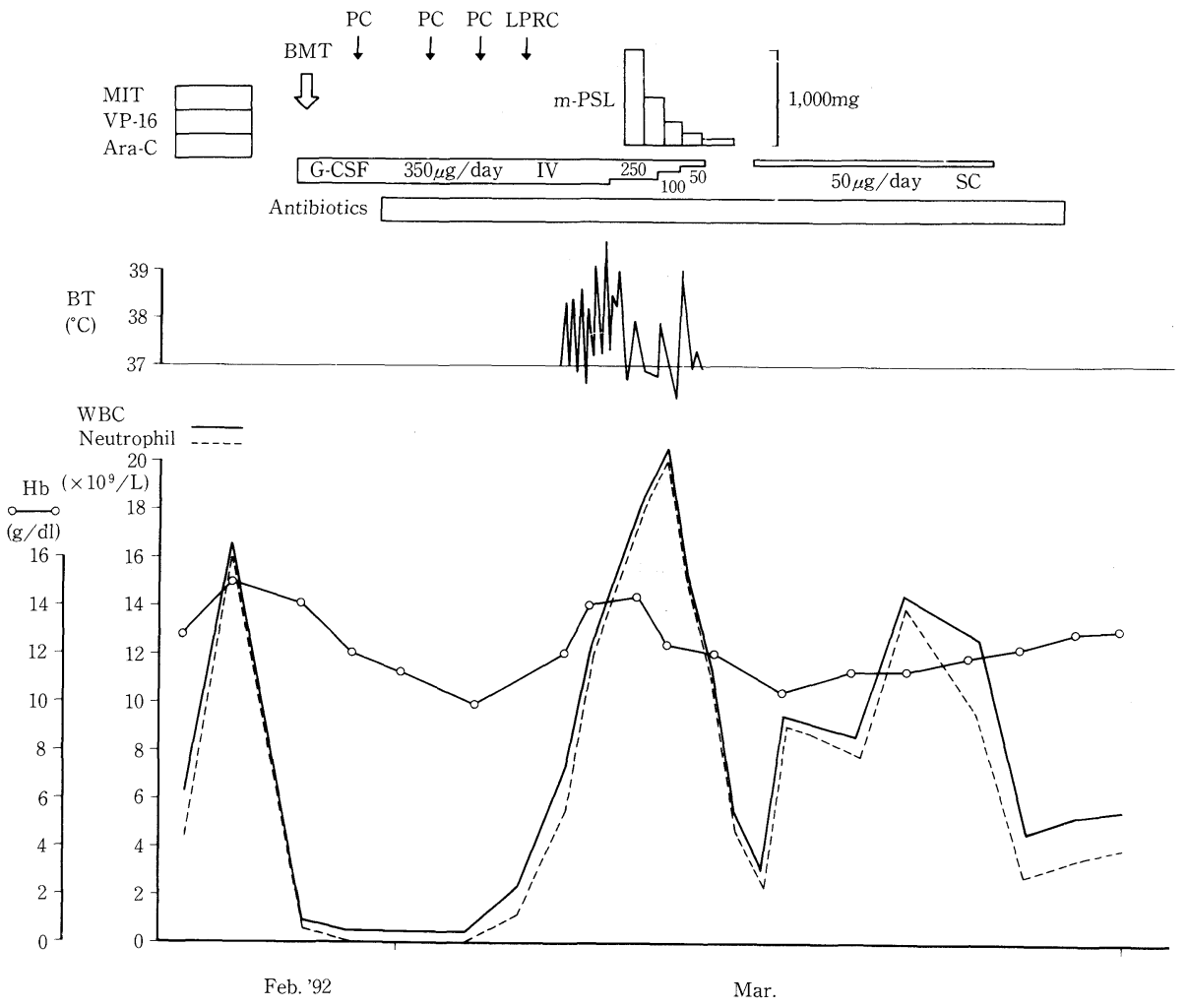

Fig. 1. Clinical course of patient 1. BMT: bone marrow transplantation, PC: platelet concentrate, LPRC: leukocyte-poor red cells, m-PSL: methylprednisolone. Methylprednisolone was administered initially at $1,000 \mathrm{mg} /$ day followed by tapered doses.

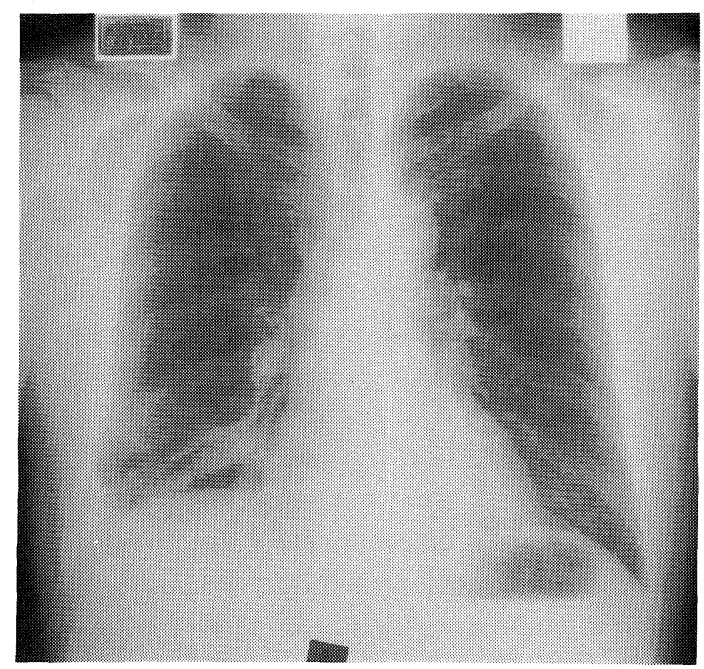

Fig. 2. Chest X-ray of patient 1,14 days after autologous bone marrow transplantation. Pleural effusions of right lung were observed.

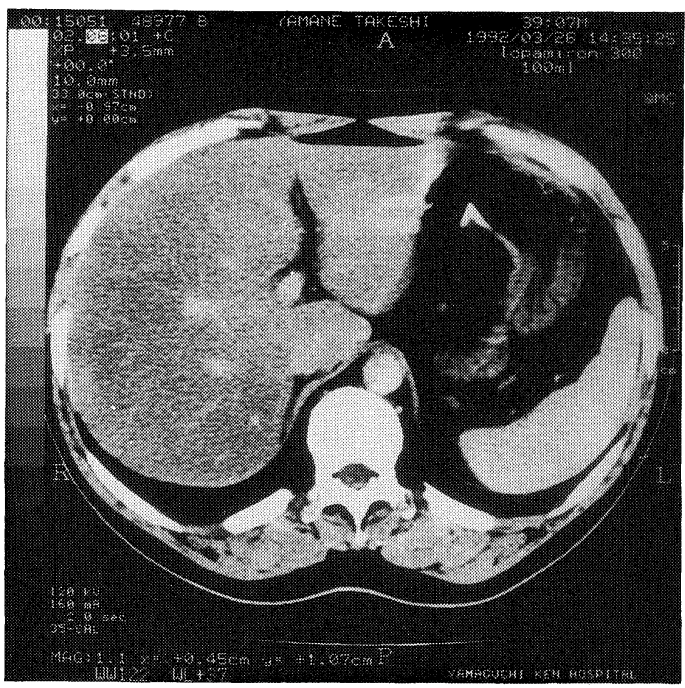

Fig. 3. Liver computed tomography of patient 1,21 days after bone marrow transplantation. Diffuse low density lesion of the right lobe was observed. day 21, a low density liver lesion suggestive of an abscess appeared on computed tomography (CT) (Fig. 3). Blood chemistry findings were; total bilirubin $0.3 \mathrm{mg} / \mathrm{dl}$, direct bilirubin 0.1 $\mathrm{mg} / \mathrm{dl}$, GOT $19 \mathrm{u}$, GPT $50 \mathrm{u}, \gamma$-GTP 266 u, LDH 583 u, ALK-
P $157 \mathrm{u}$, cholesterol $157 \mathrm{mg} / \mathrm{dl}$, and blood sugar was $174 \mathrm{mg} / \mathrm{dl}$. Liver CT findings became normal on day 31 . 


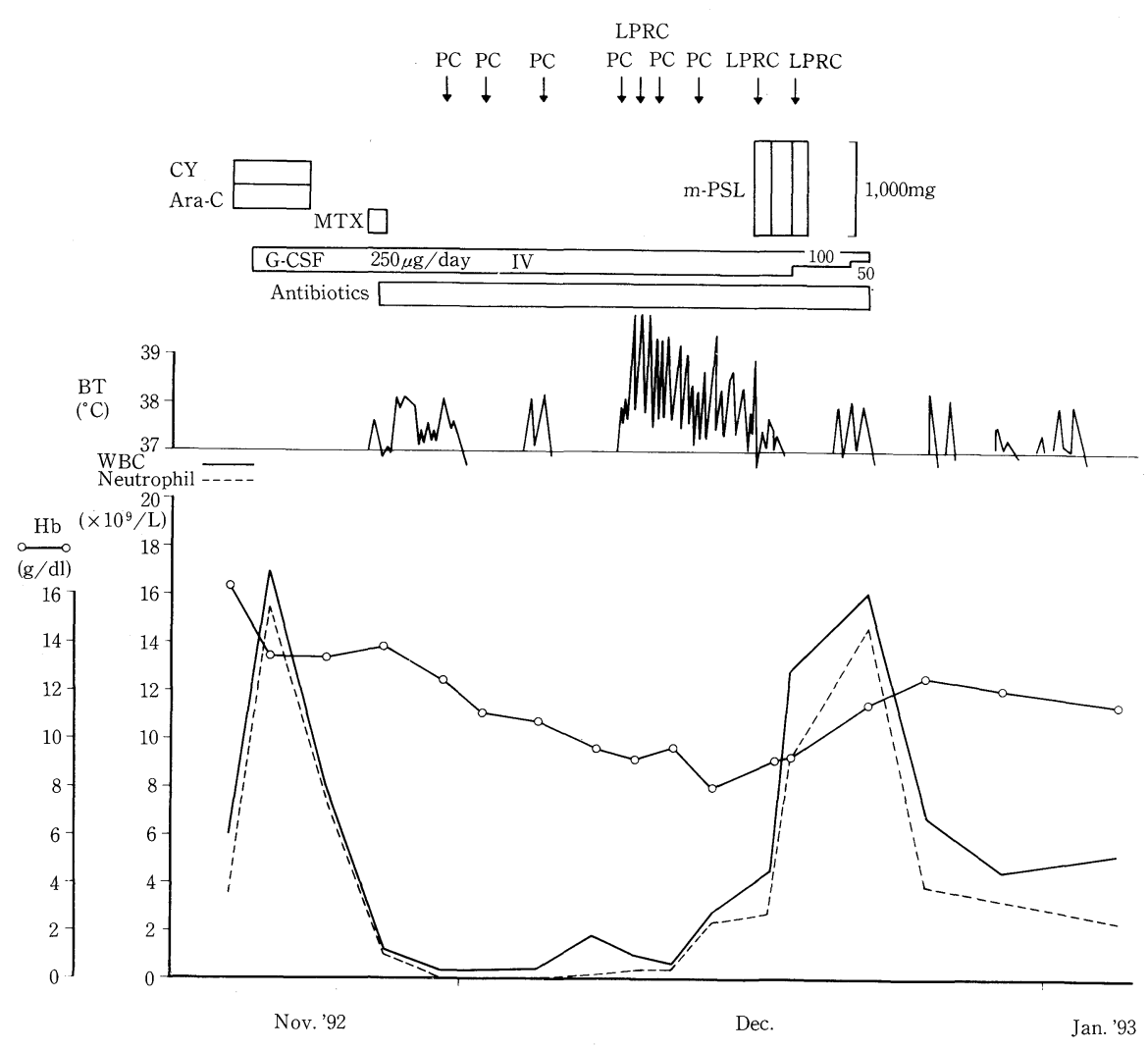

Fig. 4. Clinical course of the patient 2.

\section{Case 2}

A 38-year-old male was diagnosed with malignant lymphoma of the cervical spinal cord at the C3 level on July 1991. He received radiation of 4,400 cGy and two courses of chemotherapy. He entered into complete remission and was discharged on December 1991. In November 1992, he suffered from newly appearing left hemiplegia and was diagnosed with relapse in the spinal cord at the $\mathrm{C} 2$ level from the magnetic resonance imaging findings. Chemotherapy was started on November 18, consisting of cyclophosphamide (CY) 1g/day, Ara-C 1g/day, from day 1 to day 5, and methotrexate (MTX) 3g/ day on day 8 (Fig. 4). The administration of G-CSF, $250 \mu \mathrm{g} /$ day by intravenous infusion was begun on day 2 . On day 20 , the granulocyte count began to increase. On day 21, high fever over $40^{\circ} \mathrm{C}$ appeared when the granulocytes had increased to $0.2 \times 10^{9}$ / L. On day 26 , he complained of edema of the bilateral lower legs and palms and hypotension. The serum albumin level, $3.3 \mathrm{~g} / \mathrm{dl}$ on day 20 , decreased to $2.4 \mathrm{~g} / \mathrm{dl}$ on day 26 , and the hematocrit value, $27.9 \%$ on day 20 decreased to $22.7 \%$ on day 26 . The discrepancy between serum albumin and hematocrit was due to the bone marrow suppression after chemotherapy. On day 27, pleural effusion appeared on the chest $\mathrm{X}$-ray when the granulocytes increased to $2.3 \times 10^{9} / \mathrm{L}$ (Fig. 5). On day 28 , he complained of dyspnea and $\mathrm{PO}_{2}$ was $59.9 \mathrm{mmHg}$ and $\mathrm{PCO}_{2}$ was $29.4 \mathrm{mmHg}$, and CRP was $27.0 \mathrm{mg} / \mathrm{dl}$. In this term, serial blood cultures were performed, but, no evidence of bacterial or fungal infections was found. An oxygen mask was supplied and pulse

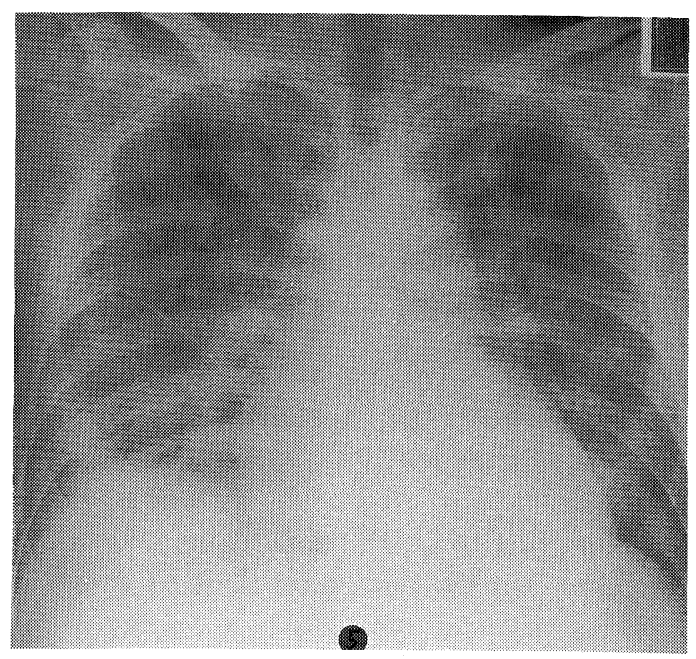

Fig. 5. Chest x-ray of the patient 2, 27 days after chemotherapy. Pulmonary congestion and pleural effusion were observed.

therapy with m-PSL and administration of catecholamines were initiated, and the dose of G-CSF was reduced and then administration was stopped. These symptoms disappeared until day 34 . The patient subsequently received a super-high dose of chemotherapy and autologous bone marrow transplantation combined with G-CSF administration. This time the patient did 
not suffer from the capillary leak syndrome, and successfully recovered from bone marrow suppression.

\section{Discussion}

Capillary leak syndrome is characterized by the symtoms caused by the capillary hyperpermeability resulting in a shift of fluid and protein from the intravascular to extravascular space (9). Since our patients were critically ill when the symptoms appeared, we could not perform thoracocentesis or transbronchial lung biopsy to prove the pathological nature of the disease. Repeated blood cultures for the bacterial and fungal infections were negative. The capillary leaky syndrome of our patients was probably related to the administration of G-CSF, since the disease developed at the rapid recovery phase of granulocytes and ameliorated after reduction or cessation of G-CSF. The pathophysiological mechanism of the cytokine-induced capillary leak syndrome which is characterized mainly by the respiratory distress symptoms, resulting from the increased production and excess accumulation of the leukocytes and release of cytokines in the lungs, might involve the following observations which have effects in common or which interact: 1) Vascular permeability is increased due to the endothelial damage caused by superoxide anion radicals produced by the activated and increased granulocytes (10). 2) GM-CSF increases cell to cell adhesion and the surface expression of adhesion-promoting surface glycoproteins on mature granulocytes $(11,12)$. GM-CSF also promotes leukocyte adherence to capillary endothelial cells and extracellular matrix, mediated by integrins (leukocyte adhesion receptors) (13). 3) Administration of GM-CSF was immediately followed by transient neutropenia, and evidence of pulmonary granulocyte sequestration was observed (14). 4) Fluid retension resulting from extravasation of intravascular fluid occurs due to the administration of TNF (7), IL-2 $(6,15)$, and also due to GMCSF in which the production of TNF by macrophage is enhanced by GM-CSF (16). 5) GM-CSF activates T cells, thus causing increased IL-2 production (17). The mechanism by which G-CSF causes capillary leak syndrome is not known, and we speculate that the phenomena sited above, is the result of the increased and activated granulocytes by G-CSF administration, and the sharing of effects via the cytokine network, may be responsible for the pathogenesis. A similar situation was recently reported, when all-trans retnoic acid was used to induce leukocyte differentiation and hematological remission in patients with promyelocytic leukemia, a potentially lethal syndrome of pulmonary infiltration developed; this was usually accompanied by peripheral blood leukocytosis (18).

Sequestration and aggregation of granulocytes might also occur in organs other than the lung or skin $(1-4,14,19-21)$. To our knowledge, this is the first report of an abscess-like lesion in the liver detected graphically by $\mathrm{CT}$ as a low density lesion probably due to the accumulation of the leukocytes, although this was not proved histologically by liver biopsy. Liver toxicity by GM-CSF was only measured by liver enzyme elevation (22).

It is not known whether these complications could also occur in a particular situation, e.g., in the rapid recovery phase of hematopoiesis following super high-dose chemotherapy, after which bone marrow recovery is enhanced by G-CSF. In such a case, rapid mobilization of granulocytes might cause uneven distribution of the increased granulocytes in certain organs. Or, alternatively it could be merely the result of leukocytosis enhanced by G-CSF. Not all of the patients with enhanced leukocytosis by G-CSF or GM-CSF had such serious complications. These complications can also occur in patients who do not have leukocytosis (18).

Beneficial effects of dexamethasone in blocking the capillary leak syndrome have been reported in patients who received IL-2 as cancer treatment $(23,24)$. In our patients, methylprednisolone was effective, along with cessation or reduction of the dose of G-CSF.

The clinical features of G-CSF-induced capillary leak syndrome are distinct, and could be separated from the septicemia or bacterial pneumonia which frequently occurs during episodes of nadir of neutrophils. In the present patient, these complications disappeared soon after granulocyte count was normalized, and the intensive treatment for infection was not necessary although a regular dose of antibiotics was administered until reaching hematological stability.

\section{References}

1) Brandt SJ, Peters WP, Atwater SK, et al. Effect of recombinant human granulocyte-macrophage colony-stimulating factor on hematopoietic reconstitution after high-dose chemotherapy and autologous bone marrow transplantation. N Engl J Med 318: 869, 1988.

2) Antman KS, Griffin JD, Elias A, et al. Effect of recombinant human granulocyte-macrophage colony-stimulating factor on chemotherapyinduced myelosuppression. N Engl J Med 319: 593, 1988.

3) Lieschke GJ, Burgess AW. Granulocyte colony-stimulating factor and granulocyte-macrophage colony-stimulating factor. First of two parts. N Engl J Med 327: 28, 1992.

4) Lieschke GJ, Burgess AW. Granulocyte colony-stimulating factor and granulocyte-macrophage colony-stimulating factor. Second of two parts. N Engl J Med 327: 99, 1992.

5) Emminger W, Emminger-Schmidmeier W, Peters $C$, et al. Capillary leak syndrome during low dose granulocyte-macrophage colony-stimulating factor (rh GM-CSF) treatment of a patient in a continuous febrile state. Blut 61: 219, 1990

6) Margolin KA, Rayner AA, Hawkins MJ, et al. Interleukin-2 and lymphokine-activated killer cell therapy of solid tumors: analysis of toxicity and management guidelines. J Clin Oncol 7: 486, 1989.

7) Morice RC, Blick MB, Ali MK, Gutterman JU. Pulmonary toxicity of recombinant tumor recrosis factor (rTNF). Proc Am Soc Clin Oncol 6: 29, 1987.

8) Hollingshead LM, Goa KL. Recombinant granulocyte colony-stimulating factor (rG-CSF). A review of its pharmacological properties and prospective role in neutropenic conditions. Drugs 42: 300, 1991.

9) Teelucksingh S, Padfield PL, Edwards CRW. Systemic capillary leak syndrome. Q J Med 75: 515, 1990.

10) Sacks T, Moldow CF, Craddock PR, Bowers TK, Jacob HS. Oxygen radicals mediate endothelial cell damage by complement-stimulated granulocytes. J Clin Invest 61: 1161, 1978.

11) Arnaout MA, Wang EA, Clark SC, Sieff CA. Human recombinant granulocyte-macrophage colony-stimulating factor increases cell-to-cell adhesion and surface expression of adhesion-promoting surface glycoproteins on mature granulocytes. J Clin Invest 78: 597, 1986.

12) Socinski MA, Cannistra SA, Sullivan R, et al. Granulocyte-macrophage 


\section{Capillary Leak Syndrome due to G-CSF}

colony-stimulating factor induces the expression of the CD11b surface adhesion molecule on human granulocytes in vivo. Blood 72: 691, 1988.

13) Springer TA. Adhesion receptors of the immune system. Nature 346: 425 , 1990.

14) Devereux S, Linch DC, Costa DC, Spittle MF, Jelliffe AM. Transient leukopenia induced by granulocyte-macrophage colony-stimulating factor. Lancet 2: 1523, 1987.

15) Rosenstein M, Ettinghausen SE, Rosenberg SA. Extravasation of intravascular fluid mediated by the systemic administration of recombinant interleukin 2. J Immunol 137: 1735, 1986.

16) Cannistra SA, Rambaldi A, Spriggs DR, Hermann F, Kufe D, Griffin JD. Human granulocyte-macrophage colony-stimulating factor induces expression of the tumor necrosis factor gene by the U937 cell line and by normal human monocytes. J Clin Invest 79: 1720, 1987.

17) Morrissey PJ, Bressler L, Park LS, Alpert A, Gillis S. Granulocytemacrophage colony-stimulating factor augments the primary antibody response by enhancing the function of antigen-presenting cells. J Immunol 139: $1113,1987$.

18) Frankel SR, Eardley A, Lauwers G, Weiss M, Warrell RP. The retinoic acid syndrome in acute promyelocytic leukemia. Ann Intern Med 117: 292, 1992.

19) Ross HJ, Moy LA, Kaplan R, Figlin RA. Bullous pyoderma gangrenosum after granulocyte colony-stimulating factor treatment. Cancer 68: 441, 1991.

20) Wodzinski MA, Hampton K, Reilly JT. Differential effect of G-CSF and GM-CSF in acquired neutropenia. Br J Haematol 77: 249, 1991.

21) Dreicer R, Schiller JH, Carbone PP. Granulocyte-macrophage colonystimulating factor and vasculitis. Ann Intern Med 111: 91, 1989.

22) Cebon J, Lieschke GJ, Bury RW, Morstyn G. The dissociation of GMCSF efficacy from toxicity according to route of administration: a pharmacodynamic study. Br J Haematol 80: 144, 1992.

23) Vetto JT, Papa MZ, Lotze MT, Chang AE, Rosenberg SA. Reduction of toxicity of interleukin-2 and lymphokine-activated killer cells in humans by the administration of corticosteroids. J Clin Oncol 5: 496, 1987.

24) Mier JW, Vachino G, Klempner MS, et al. Inhibition of interleukin-2induced tumor necrosis factor release by dexamethasone: prevention of an acquired neutrophil chemotaxis defect and differential suppression of interleukin-2-associated side effects. Blood 76: 1993, 1990. 